Biochimica et Biophysica Acta, 441 (1976) 280-293

(c) Elsevier Scientific Publishing Company, Amsterdam - Printed in The Netherlands

BBA 56829

\title{
ACTIVITY AND PROPERTIES OF CTP: CHOLINEPHOSPHATE CYTIDYLYLTRANSFERASE IN ADULT AND FETAL RAT LUNG *
}

\author{
WILLIAM STERN, CECILIA KOVAC and PAUL A. WEINHOLD ** \\ Veterans Administration Hospital and Department of Biological Chemistry, University of \\ Michigan Medical School, Ann Arbor, Mich. (U.S.A.)
}

(Received February 11th, 1976)

\section{Summary}

Choline, hosphate cytidylyltransferase (CTP : cholinephosphate cytidylyltransferase, EC 2.7.7.15) is located in both the microsomal and supernatant fractions of adult lung when the tissue is homogenized in $0.145 \mathrm{M} \mathrm{NaCl}$. The activity is located predominantly in the supernatant fraction in fetal lung. Cholinephosphate cytidylyltransferase in the supernatant from fetal lung is stimulated 4- to 6-fold by the additions of total lung lipid. Serine phosphoglycerides and inositol phosphoglycerides specifically caused stimulation whereas choline phosphoglycerides and ethanolamine phosphoglycerides produced no stimulation. Lysophosphatidylcholine cause some stimulation, but only at high concentrations. A number of detergents were investigated. All produced inhibition except for the ampholytic detergent, miranol H2M which was not inhibitory. None of the detergents produced any stimulation of activity. Cytidylyltransferase activity in fetal lung when assayed in the absence of lipid is about $25 \%$ of the adult. The activity when assayed in the presence of lipid is equal or slightly higher than adult levels. The activity, measured without added phospholipid, increases 5 - to 6 -fold within $12 \mathrm{~h}$ after birth, to values higher than in the adult. The activity, measured in the presence of phospholipid, increased almost linearly from -2 day until +1 day. There is an inverse relationship between the concentration of phospholipid in the fetal lung supernatant and the degree of lipid stimulation. Chromatographic experiments with Biogel A 1.5 columns have shown that cytidylyltransferase can exist in two molecular sizes, a small molecular size that requires phospholipid for activity, and a larger molecular weight species which does not require the addition of phospholipid for activity. Fetal lung has a higher proportion of the low molecular weight

\footnotetext{
* A preliminary communication of some of these results was presented by W. Stern and P.A. Weinhold, at the 56th Federation of American Societies for Experimental Biology, April 9-14, 1972.

** To whom correspondence and reprint requests should be addressed.
} 
form than adult lung. The small molecular weight species can be converted to the larger molecular weight form by the addition of phospholipids.

\section{Introduction}

The concentration of choline phosphoglycerides in the lungs of fetal rats increases with development from a level of about $50 \%$ of the adult value at 19-20 days gestation to nearly adult levels by birth [1]. The increase in choline phosphoglyceride content coincides with the appearance in the lung of pulmonary surfactant [2], a material rich in 1,2-dipalmitoyl-sn-glycero-3phosphocholine $[3,4]$. Choline phosphoglycerides are synthesized by lung primarily by the CDPcholine pathway [5-9] and this pathway has been shown to increase together with the developmental rise in choline phosphoglyceride concentration [5].

During studies on the incorporation of $\left[\mathrm{CH}_{3}{ }^{14} \mathrm{C}\right] \mathrm{choline}$ into choline phosphoglycerides by fetal lung slices, we found that when the incorporation of radioactive choline into choline phosphoglycerides was low, there was a high concentration of phosphorylcholine. As the rate of incorporation of choline into choline phosphoglycerides increased with development, the concentration of phosphorylcholine decreased [5]. These results suggest that the developmental increase in the incorporation of choline may result from increases in the conversion of phosphorylcholine to CDPcholine. Therefore, we felt that a detailed study of the activity and properties of phosphorylcholine cytidylyltransferase during lung development was crucial for an understanding of the mechanism associated with the developmental changes in the synthesis of choline phosphoglycerides.

\section{Materials and Methods}

\section{Materials}

Pregnant and non-pregnant $(180-200 \mathrm{~g})$ rats were obtained from Holtzman Company. The age of the fetuses was determined by considering the sperm positive date as day zero.

Phosphorylcholine, cytidine triphosphate (type IV salt), cytidine diphosphocholine, and bovine serum albumin were purchased from Sigma. Sodium deoxycholate and Tween-20 (polyoxyethylene glycol sorbitan monolaurate) were obtained from Difco Laboratories and Mann Research Laboratories, respectively. Lubrol WX (polyoxyethylene glycol cetyl-stearyl alcohol) and sodium dodecyl sulfate were obtained from Sigma Chemical Co. Atlas G 3634 A was purchased from Atlas Chemical Division, Wilmington, DE. Nonidet P 40 (polyoxyethyleneglycol(9)p-tert-octylphenol) was obtained from Particle Data Laboratories, Elmhurst, Illinois. Sodium deoxycholate and Triton X100 (polyoxyethuleneglycol $(9-10)$ p-tert-octylphenol) were obtained from Fisher Chemical Co. Miranol H2M (2-undecyl-1-(sodium carboxymethyl)-2 [2-sodium carboxymethoxy)ethyl]-2-imidazolinium hydroxide) was purchased from Miranol Chemical Co., Irvington, New Jersey. $\left[\mathrm{CH}_{3}-\mathrm{C}^{14}\right]$ Phosphocholine was obtained from New England Nuclear Corporation. Unisil, silicic 
acid for column chromatography, was purchased from Clarkson Chemical Co. Silica gel HR was obtained from Brinkman Instruments. DEAE-cellulose (DE 22 , fibrous) was obtained from Reeve Angel. Choline phosphoglycerides, serine phosphoglycerides, ethanolamine phosphoglycerides, and inositol phosphoglycerides were purchased from Applied Sciences Laboratories. Lysophosphatidylcholine and lysophosphatidylethanolamine were obtained from Serdary Research Laboratories, London, Ontario, Canada. These lipids migrated as single spots on thin-layer chromatography in the solvent system chloroform/ methanol/acetic acid/water (100:60:16:8, by vol.). Lysophosphatidylcholine was also prepared from lung choline phosphoglycerides by hydrolysis with phospholipase A [10] followed by purification by thin-layer chromatography. Biogel A 1.5 was obtained from Bio Rad Laboratories, Richmond, California. Phospholipase A from bee venom was purchased from Sigma.

\section{Tissue preparation}

Lungs from fetal and adult rats were removed and placed in a beaker on ice. The lungs from several fetuses were combined to obtain the necessary amount of tissue. The lungs were minced thoroughly with scissors and homogenized in 5 vols. of $0.145 \mathrm{M} \mathrm{NaCl}$ with a Potter-Elvehjem type homogenizer. The homogenates were centrifuged at $600 \times g$ for $10 \mathrm{~min}$ to obtain a crude nuclei and debrie pellet. The $600 \times g$ supernatant was centrifuged at $8000 \times g$ for 10 $\min$ to sediment the mitochondria fraction. The $8000 \times g$ supernatant was centrifuged at $100000 \times \mathrm{g}$ for $60 \mathrm{~min}$ to obtain a pelleted microsomal fraction and a supernatant fraction.

\section{Measurement of phosphorylcholine cytidylyltransferase activity}

The standard incubation mixture contained $20 \mathrm{mM}$ Tris-maleate $\mathrm{pH} \mathrm{6.0,12}$ $\mathrm{mM}$ magnesium acetate, $1.5 \mathrm{mM}$ dithiothreitol, $0.5 \mathrm{mM}$ EDTA, $4.0 \mathrm{mM} \mathrm{CTP}$, and $1.6 \mathrm{mM}\left[\mathrm{CH}_{3^{-}}{ }^{14} \mathrm{C}\right]$ phosphocholine $(1000 \mathrm{cpm} / \mathrm{nmol})$. In some experiments $20 \mathrm{mM}$ potassium phosphate buffer $\mathrm{pH} 6.0$, was used in place of the Trismaleate and gave similar activities. Lung lipids or isolated phospholipids were added to the assay as suspensions, prepared as described below. The assay was started by the addition of enzyme preparation and incubated for $10 \mathrm{~min}$ at $37^{\circ} \mathrm{C}$. The reaction was stopped by placing the tubes in a boiling water bath for $2 \mathrm{~min}$. The radioactive CDPcholine formed by the reaction was isolated by absorption onto charcoal followed by elution as described by Ansell and Chojnacki [11] with the following modifications. After the reaction was stopped by boiling, $0.4 \mathrm{ml}$ of charcoal mixture $(1.0 \mathrm{~g}$ acid-washed Norit A in $25 \mathrm{ml}$ of 20 $\mathrm{mM}$ phosphocholine) was added. After 3 washes with $10 \mathrm{ml}$ of water, the CDPcholine was eluted from the charcoal with $1.0 \mathrm{ml}$ of ethanol/concd $\mathrm{NH}_{4} \mathrm{OH}$ / water ( $60: 3: 37$, by vol.) in a boiling water bath for 30 min followed by two additional extractions with $1.0 \mathrm{ml}$ of the extraction mixture. This procedure gave an essentially complete recovery of CDPcholine. Isolation of CDPcholine by paper chromatography [10] gave results identical to those with the charcoal assay.

The reaction velocity was constant for $20 \mathrm{~min}$ with either adult or fetal supernatant preparations. The rate of the reaction was proportional to the 
amount of supernatant for both fetal and adult preparations, if the amount of supernatant did not exceed $2 \mathrm{mg}$ protein $/ \mathrm{ml}$ reaction mixture.

\section{Isolation and purification of lung phospholipids}

Lipid was extracted from adult lung essentially as described by Folch et al. [12]. The lipid was initially fractionated by silicic acid-column chromatography as described by Sweeley [13]. This procedure produced partially purified ethanolamine phosphoglycerides, a fraction that contained both serine phosphoglycerides and inositol phosphoglycerides, partially purified choline phosphoglycerides and a fraction that contained both sphingomylin and lysophosphatidylcholine. Pure ethanolamine phosphoglycerides, serine phosphoglycerides and inositol phosphoglycerides were prepared from these fractions by DEAE-cellulose chromatography [14], followed by preparative thin-layer chromatography. Choline phosphoglycerides and lysophosphatidylcholine were purified further by preparative thin-layer chromatography. The preparative thin-layer chromatography was performed on plates coated with silica gel HR. The plates were developed in the solvent system chloroform/methanol/acetic acid/water (100:60:16:8, by vol.). The individual phospholipids were identified and recovered as described previously [1].

Lung phospholipids were also fractionated by high-pressure liquid chromatography on silicic acid prepacked columns (Size A silica gel 60, EM Laboratories, Elmsford, New York). The column was equilibrated on the solvent system chloroform/methanol/acetic acid/water $(50: 30: 8: 4$, by vol.). Phospholipids, previously separated from neutral lipids by a silica gel column [21], were applied and eluted with the same solvent system at a flow rate of $50 \mathrm{ml} / \mathrm{h}$. Four fractions were obtained; I, containing ethanolamine phosphoglycerides and serine phosphoglycerides; II, containing primarily inositol phosphoglycerides; III, containing choline phosphoglycerides and IV, containing sphingomylin. The entire fractionation was completed in less than $4 \mathrm{~h}$.

Phospholipids were judged to be pure when they migrated as a single spot by thin-layer chromatography in the following solvent systems: chloroform/ acetone/methanol/acetic acid/water (5:2:1:1:0.5, by vol.), chloroform/ methanol/ammonia (65:35:5, by bol.), and chloroform/methanol/acetic acid/water (100:60:16:8, by vol.). The identity of the phospholipids was verified by comparing their chromatographic mobility with standard phospholipids and by their reaction to specific developing reagents [15]. The purified phospholipids were stored under nitrogen at $-40^{\circ} \mathrm{C}$.

\section{Preparation of lipid suspensions}

An aliquot of a chloroform solution of lipid was pipetted into a $17 \times 65 \mathrm{~mm}$ glass vial. After the chloroform was evaporated under a gentle stream of nitrogen, $0.145 \mathrm{M} \mathrm{NaCl}$ was added to the tube so that the final concentration of total phospholipid did not exceed $200 \mu \mathrm{g} / \mathrm{ml}$. The mixture was sonicated in an ice bath for $30 \mathrm{~s}$ using a Branson sonifier, Model S110, at a setting of 3 and an amperage reading of 3.5. Phosphorus analysis of the sonicates showed that they contained the concentration of phospholipid predicted from the chloroform aliquot. Lipid suspensions were used immediately after sonication. 
Analytical procedures

Protein determinations were carried out according to the method of Lowry et al. [16] with bovine serum albumin as the standard. Lipid phosphorus was determined as previously described [1].

\section{Results}

Subcellular distribution of fetal and adult enzymes

Significant amounts of cytidylyltransferase activity were found in both the supernatant and microsomes when adult lung was fractionated in $0.145 \mathrm{M} \mathrm{NaCl}$ (Table I). Homogenization in $0.25 \mathrm{M}$ sucrose or water resulted in less activity in the $600 \times g$ supernatant and a corresponding lower activity in the microsomes. The amount of cytidylyltransferase activity recovered in the $100000 \times g$ supernatant was similar in all three homogenization mediums.

The activity in fetal lung is significantly increased by the addition of lung lipid to the reaction mixture, a phenomena that will be presented in more detail in a subsequent part of this paper. The cytidylyltransferase activity in the fetal lung, when assayed in the presence of lipid, is predominantly located in the $100000 \times g$ supernatant (Table I). In absence of lipid, the activity in the supernatant is greatly reduced. The apparent difference between the subcellular distribution of activity in the presence and absence of lipid is largely a result of the stimulatory effect of lipid on the activity in the $100000 \times g$ fraction.

The effect of lipids on cytidylyltransferase activity in the supernatant fraction

Cytidylyltransferase activity in the supernatant fraction from fetal lung was stimulated more than 7 -fold by the addition of lung lipid to the assay mixtures (Table II). However, cytidylyltransferase activity in adult lung supernatant was increased only slightly. The stimulatory effect was achieved with fresh supernatant preparations without any prior treatment to remove lipid from the preparation. The neutral fraction produced no stimulation, while the phospholipid fraction gave about a 4-fold stimulation. The phospholipid fraction was

TABLE I

SUBCELLULAR DISTRIBUTION OF CYTIDYLYLTRANSFERASE IN ADULT AND FETAL LUNG.

Lung was homogenized in $0.145 \mathrm{M} \mathrm{NaCl}$. The activity is expressed as $\mu \mathrm{mol} / \mathrm{min}$. The "+ lipid" represents the activity obtained when the reaction mixture contained phospholipid $(0.8 \mathrm{mM})$ that was obtained from adult lung.

\begin{tabular}{|c|c|c|c|c|c|c|}
\hline \multirow[t]{3}{*}{ Fraction } & \multicolumn{6}{|c|}{ Total (\%) } \\
\hline & \multirow{2}{*}{\multicolumn{2}{|c|}{ Adult }} & \multicolumn{4}{|c|}{ Fetal $(-2$ day $)$} \\
\hline & & & --lipid & & +lipid & \\
\hline $600 \times g$ supernatan $t$ & 50 & 100 & 47 & 100 & 127 & 100 \\
\hline Mitochondria & 2.5 & 5 & 14 & 33 & 8 & 6 \\
\hline Microsomes & 17 & 34 & 16 & 33 & 10 & 7 \\
\hline Supernatant & 30 & 60 & 12 & 32 & 104 & 86 \\
\hline Recovery & 49.5 & 99 & 42 & 89 & 122 & 96 \\
\hline
\end{tabular}


TABLE II

STIMULATION OF CYTIDYLYLTRANSFERASE ACTIVITY IN LUNG SUPERNATANT BY LIPIDS

Lung lipid refers to the total lipid fraction from rat lung. The lipid was added to the assay at $1.0 \mathrm{mM}$, based upon lipid phosphorus. Neutral lipid and phospholipid were added in amounts equal to that contained in the $1.0 \mathrm{mM}$ total lipid. The neutral lipid and phospholipid fraction were obtained by silicic acid column chromatography of the total lipid [17].

\begin{tabular}{lll}
\hline Enzyme source & Additions & Activity (nmol/min per mg protein) \\
\hline Adult & 0 & 1.20 \\
Adult & Lung lipid & 2.00 \\
-3 Day fetal & 0 & 0.80 \\
& Lung lipid & 5.80 \\
& Neutral lipid & 0.83 \\
& Phospholipid & 3.56 \\
\hline
\end{tabular}

about $70-80 \%$ as active as the unfractionated lipid on a lipid phosphorus basis.

Purified serine phosphoglycerides and inositol phosphoglycerides gave 5to 6-fold stimulation of cytidylyltransferase activity (Fig. 1). Ethanolamine phosphoglycerides and choline phosphoglycerides were ineffective. Serine phosphoglycerides and inositol phosphoglycerides were more active than the total lipid at concentrations below $0.1 \mathrm{mM}$. However, at higher concentrations, total lipid produced a stimulation that was larger than could be obtained with either serine phosphoglycerides or inositol phosphoglycerides. Lysophosphatidylcholine, isolated from lung, was not active at concentrations up to $0.16 \mathrm{mM}$. Lysophosphatidylcholine, prepared from lung choline phosphoglycerides, gave no stimulation at a concentration of $1.0 \mathrm{mM}$. When the concentration was raised further to 2.0 and $3.0 \mathrm{mM}$, a 2- to 3-fold stimulation could be obtained. Thus, lysophosphatidylcholine produced significant stimulation of cytidylyl-

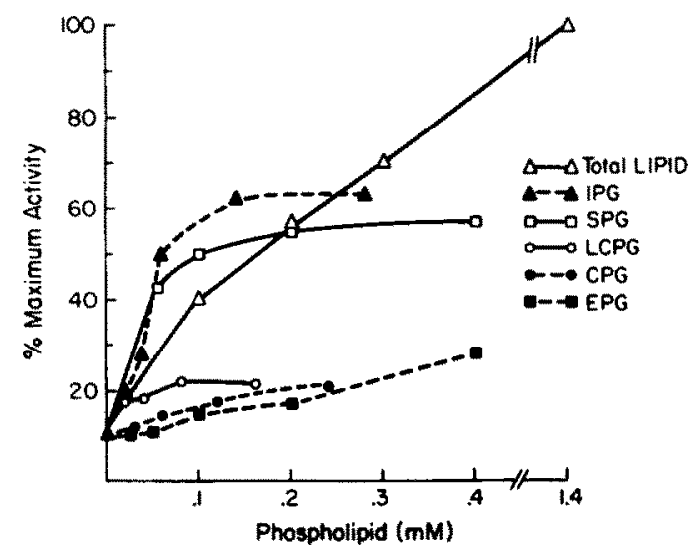

Fig. 1. The stimulation of fetal eytidylyltransferase activity by specific phospholipids. The total lipid refers to the chloroform/methanol extract from rat lung. The $100000 \times g$ supernatant from -3 day fetal lung was used as the source of cytidylyltransferase. Maximal activity was $0.35 \mathrm{nmol} / \mathrm{min}$. The abbreviations are: inositol phosphoglycerides, IPG; serine phosphoglycerides, SPG; lysphophosphatidylcholine, LCPG; choline phosphoglycertdes, CPG; ethanolamine phosphoglycerides, EPG. 
transferase activity only at concentrations 40 times higher than required for inositol phosphoglycerides and serine phosphoglycerides.

The stimulation produced by serine phosphoglycerides and inositol phosphoglycerides was not additive since the increase in activity achieved with $0.1 \mathrm{mM}$ inositol phosphoglycerides was not altered by the addition of $0.2 \mathrm{mM}$ serine phosphoglycerides, the activity was the same in the presence of either $0.1 \mathrm{mM}$ inositol phosphoglycerides or $0.2 \mathrm{mM}$ serine phosphoglycerides. The addition of $0.3 \mathrm{mM}$ choline phosphoglycerides did not change the stimulation produced with $0.1 \mathrm{mM}$ inositol phosphoglycerides. The addition of neutral lipids to either total phospholipids or purified individual phospholipids produced no change in the stimulatory activity of the phospholipids.

Several commercial preparations of inositol phosphoglycerides and serine phosphoglycerides from bovine liver did not give significant stimulation even after further purification by preparative thin-layer chromatography. The inability of commercial lipid preparation to activate lipid-requiring systems is not an uncommon observation. Levey [18], for example, found that only one purified preparation of inositol phosphoglycerides was capable of restoring the catecholamine response of adenylate cyclase, whereas several commercial preparations were inactive.

During the course of these investigations, we routinely used total lung lipids for stimulation experiments. The total lipid fraction gradually lost its stimulabory activity. When the lipid was stored at $-20^{\circ} \mathrm{C}$, about $50 \%$ of the stimulatory activity was lost after 2 months.

The lack of activity with commercial preparation, the gradual decline in activity of total lipid during storage and the inability to obtain equivalent stimulations with isolated phospholipids suggest that the phospholipids species active in the stimulation phenomena may be slowly destroyed during storage and may be more rapidly inactivated during the isolation and purification processes. In support of this conclusion we found that inositol phosphoglycerides, rapidly isolated by high-pressure chromatography, produced stimulations of cytidylyltransferase equal to or higher than that produced with whole lung lipid.

General characteristics of cytidylyltransferase in supernatant

Cytidylyltransferase activity in adult and fetal supernatant was maximal over a rather broad pH (Fig. 2). Maximal activity was present at $\mathrm{pH} 6.0-7.5$.

The apparent $K_{\mathrm{m}}$ for phosphorylcholine with adult enzyme was estimated to be $1.0 \mathrm{mM}$ when the CTP and $\mathrm{Mg}^{2+}$ concentrations were $4.0 \mathrm{mM}$ and $12 \mathrm{mM}$, respectively. The apparent $K_{\mathrm{m}}$ for CTP with adult enzyme was $0.8 \mathrm{mM}$ when the concentrations of phosphorylcholine was $1.6 \mathrm{mM}$ and $\mathrm{Mg}^{2+}$ was $12 \mathrm{mM}$. Maximal activity was achieved when the $\mathrm{Mg}^{2+}$ concentration was equal to the CTP concentration. $\mathrm{Mg}^{2+}$ in excess of the CTP had no effect on the enzyme activity.

The inclusion of $1.0 \mathrm{mM}$ dithiothreitol or $1.0 \mathrm{mM}$ EDTA in the homogenization medium produced no significant increase in the activity in the subsequently isolated supernatant fractions. There was also no evidence of $\mathrm{Ca}^{2+}$ inhibition of cytidylyltransferase activity at $\mathrm{Ca}^{2 *}$ concentrations up to $1.0 \mathrm{mM}$. However, the addition of $0.5 \mathrm{mM}$ EDTA and $1.5 \mathrm{mM}$ dithiothreitol to the reaction $\mathrm{mix}$ ture produced a $40-50 \%$ increase in activity. 


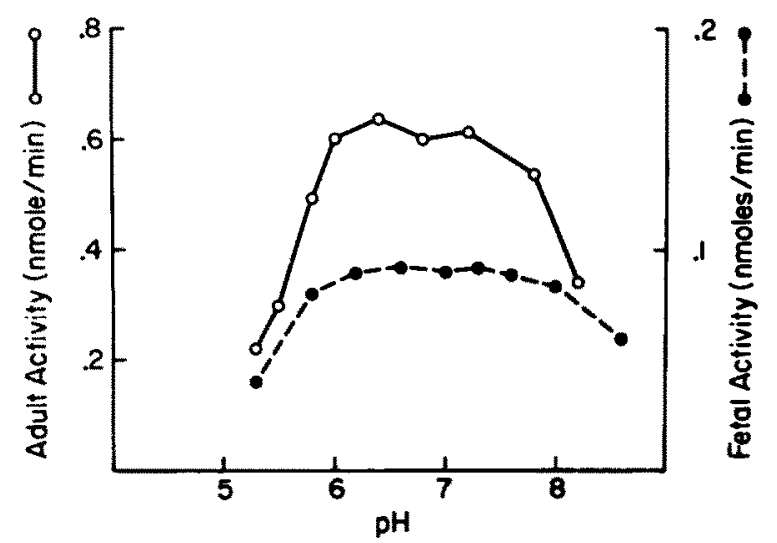

Fig. 2. The effect of $\mathrm{pH}$ on cytidylyltransferase activity. Activity was determined as described in the methods. Tris-maleate buffer was used throughout the $\mathrm{pH}$ range investigated. The pH shown is that actually measured in the reaction mixture.

\section{Effect of detergents on activity}

Table III presents the effects of several detergents on the activity of fetal cytidylyltransferase, both in the presence and absence of whole lipid. The activity in the absence of lipid was inhibited by all detergents. However, in the presence of lipid, the detergents were less inhibitory. For example, sodium deoxycholate, Triton X 100 and Nonidet P 40 in the presence of lipid produced relatively little inhibilion at $0.05 \%$ concentration, but at $0.5 \%$ concentration were strongly inhibitory. The ampholytic detergent, Miranol H2M did not significantly inhibit the activity even at $0.5 \%$ concentration. None of the detergents caused any lipid-like stimulation at the concentrations used in these experiments.

The inhibition of the activity determined in the absence of added lipid suggests that the detergents may function by displacing lipid from the enzyme when there is no appreciable lipid present in the reaction mixture. However, when relatively high amounts of lipid are also present in the reaction mixture, some detergents are not able to prevent enzyme-lipid interaction. Thus, sodium deoxycholate and Nonidet P 40 at $0.05 \%$ concentrations and Miranol H2M at both 0.05 and $0.5 \%$ do not prevent the lipid activation. Tween 20 and Triton $\mathrm{X} 100$ at $0.5 \%$ concentration can partially prevent the activation. Those detergents which strongly inhibit both in the presence and absence of lipid may irreversibly alter the enzyme independent of the enzyme-lipid interaction.

\section{Cytidylyltransferase activity during lung development}

Lungs from fetuses at different gestational ages were fractionated by differential centrifugation into a microsome and supernatant fraction. The amount of cytidylyltransferase activity in the supernatant fractions from $1.0 \mathrm{~g}$ of lung, in the presence and absence of lung lipid, is shown in Fig. 3A. The activity in the absence of added lipid is low in the fetal preparations at all prenatal ages. The activity increases almost 6 -fold between birth and one day after birth. The activity in fetal lung supernatant was increased by the addition of lung lipid to values equal to or above adult levels. In the presence of lipid, there was a 
TABLE III

EFFECT OF DETERGENTS ON CYTIDYLYLTRANSFERASE ACTIVITY.

A $28-40 \%\left(\mathrm{NH}_{4}\right)_{2} \mathrm{SO}_{4}$ fraction from -2 day fetal lung supernatant was used as the source of cy tidylyltransferase activity. Lipid from rat lung was added to the assay where indicated, at a concentration of $1.0 \mathrm{mM}$ based on total phosphorus.

\begin{tabular}{|c|c|c|c|c|c|}
\hline \multirow[t]{3}{*}{ Detergent } & \multicolumn{5}{|c|}{ Concentration activity } \\
\hline & \multirow[t]{2}{*}{$\%(w / v)$} & \multicolumn{2}{|l|}{-Lipid } & \multirow{2}{*}{$\begin{array}{l}\text { +Lipid } \\
\qquad \begin{array}{l}\text { nmol/min } \\
\text { per } \mathrm{mg}\end{array}\end{array}$} & \multirow[b]{2}{*}{ Control $(\%)$} \\
\hline & & $\begin{array}{l}\text { nmol/min } \\
\text { per mg }\end{array}$ & Control $(\%)$ & & \\
\hline None & & 0.35 & 100 & 2.8 & 100 \\
\hline \multirow[t]{2}{*}{ Sodium deoxy cholate } & 0.05 & 0.12 & 34 & 2.6 & 93 \\
\hline & 0.5 & 0 & 0 & 1.3 & 46 \\
\hline \multirow[t]{2}{*}{ Sodium dodecyl sulfate } & 0.05 & 0.16 & 45 & 1.1 & 39 \\
\hline & 0.5 & 0 & 0 & 0.3 & 10 \\
\hline \multirow[t]{2}{*}{ Lubrol WX } & 0.05 & 0 & 0 & 0.2 & 7 \\
\hline & 0.5 & 0 & 0 & 0.1 & 3 \\
\hline \multirow[t]{2}{*}{ Triton X-100 } & 0.05 & 0.1 & 28 & 2.0 & 71 \\
\hline & 0.5 & 0.1 & 28 & 0.1 & 3 \\
\hline \multirow[t]{2}{*}{ Tween 20} & 0.05 & 0 & 0 & 1.7 & 60 \\
\hline & 0.5 & 0.1 & 28 & 0.1 & 3 \\
\hline \multirow[t]{2}{*}{ Nonidet P 40} & 0.05 & 0.14 & 40 & 2.8 & 100 \\
\hline & 0.5 & 0.10 & 28 & 0 & 0 \\
\hline \multirow[t]{2}{*}{ Cetyltrimethyl ammonium bromide } & 0.05 & 0 & 0 & 0.1 & 3 \\
\hline & 0.5 & 0.1 & 28 & 0.1 & 3 \\
\hline \multirow[t]{2}{*}{ Atlas G $3634 \mathrm{~A}$} & 0.05 & 0 & 0 & 0.1 & 3 \\
\hline & 0.5 & 0 & 0 & 0.1 & 3 \\
\hline \multirow[t]{2}{*}{ Miranol H2M } & 0.05 & 0.17 & 48 & 2.8 & 100 \\
\hline & 0.5 & 0.13 & 37 & 2.6 & 92 \\
\hline
\end{tabular}

rather uniform increase in enzyme activity from -4 day to +1 day. The specific activity ( $\mathrm{nmol} / \mathrm{min} / \mathrm{mg}$ protein) of the supernatant cytidylyltransferase and the $\mathrm{mg}$ supernatant protein/g of lung are shown in Fig. 3B. The specific activity is considerably higher in fetal lung supernatant than in the adult preparations. This is a reflection of the lower protein content in fetal supernatant.

The microsomal fraction from fetal lung had consistently low cytidylyltransferase activity; it was not affected by the addition of lipid to the reaction. The activity in the microsomes increased from $8 \mathrm{nmol} / \mathrm{min} / \mathrm{g}$ tissue at -1 day to $16 \mathrm{nmol} / \mathrm{min} / \mathrm{g}$ tissue at +1 day. The activity at +1 day was essentially the same as found in adult microsomes.

Relationship between supernatant phospholipids and cytidylyltransferase activity in the supernatant

The concentration of phospholipids in the $100000 \times g$ supernatant is low in 

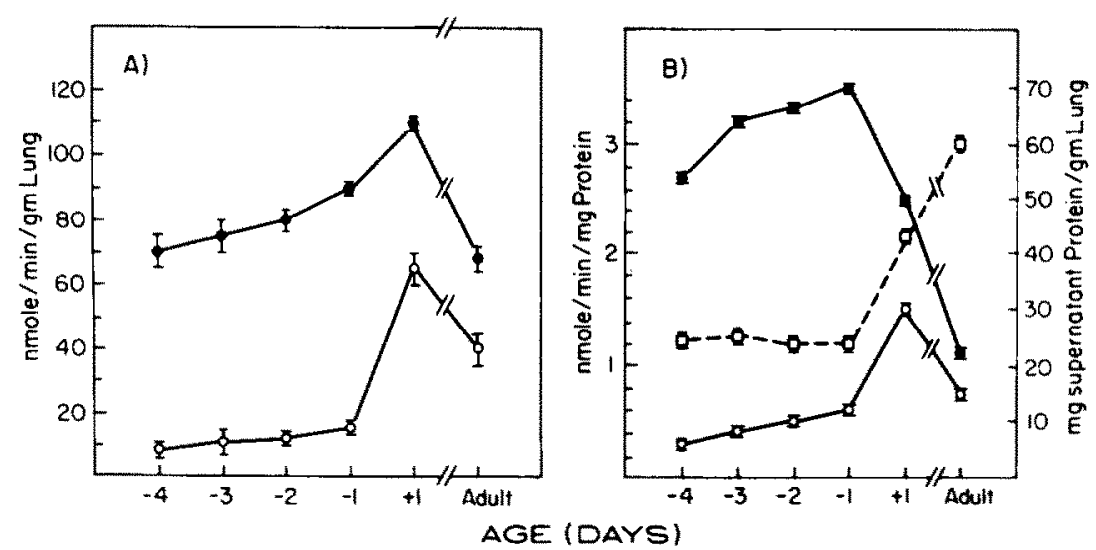

Fig. 3. Cytidylyltransferase activity during lung development. The activity was determined in $100000 \times \mathrm{g}$ supernatant from lung. Each point represents the average of at least 4 separate experiments. Each experiment involved triplicate assays of the supernatant from the pooled lungs from a single litter. Adult (200$250 \mathrm{~g}$ female) lungs were processed simultaneously with each experiment. $-\bullet$, activity in the presence of $1.0 \mathrm{mM}$ total lipid; $0-0$, activity in the absence of added lipid; $\square-\square$, supernatant protein per lung; the bars represent the S.E.M.

fetal rat lung and increases with development (Table IV). The activity of cytidylyltransferase in the supernatant increases, and the degree of stimulation produced by added lipid decreases together with the rise in phospholipid content in the supernatant.

Thin-layer chromatographic analysis of the phospholipid indicated that the relative amount of choline phosphoglycerides was higher in the supernatant than in the whole lung ( 82 vs. $48 \%$ ). This was found for both fetal and adult supernatant. The relative amount of ethanolamine phosphoglycerides was lower in supernatant than in the whole lung ( 3 vs. 18.7\%). There were no significant differences in the percent distribution of inositol phosphoglycerides and serine phosphoglycerides; however, their absolute concentrations were lower in the fetal supermatant, due to the overall lower amount of phospholipids.

\section{TABLE IV}

PHOSPHOLIPID CONCENTRATION AND CYTIDYLYLTRANSFERASE ACTIVITY IN THE 100000 $X_{g}$ SUPERNATANT.

Each value is the average $\pm S, E . M$. for the total number of separate experiments shown by numbers in parentheses.

\begin{tabular}{lllll}
\hline $\begin{array}{l}\text { Age } \\
\text { (days) }\end{array}$ & $\begin{array}{l}\text { Phospholipid } \\
(\mu \mathrm{M})\end{array}$ & $\begin{array}{l}\text { Cytidylyltransferase } \\
\text { (nmol/min per mg protein) }\end{array}$ & $\begin{array}{l}\text { +Lipid } \\
\text {-Lipid }\end{array}$ \\
\cline { 3 - 5 } & & \multicolumn{1}{l}{$\begin{array}{l}\text {-Lipid } \\
\text { +Lipid }\end{array}$} & \\
\hline$-4(5)$ & $48 \pm 8$ & $0.30 \pm 0.05$ & $2.3 \pm 0.3$ & 7.6 \\
$-3(4)$ & $90 \pm 42$ & $0.42 \pm 0.03$ & $2.8 \pm 0.2$ & 6.6 \\
$-2(4)$ & $100 \pm 24$ & $0.50 \pm 0.06$ & $2.9 \pm 0.4$ & 5.8 \\
$-1(8)$ & $152 \pm 21$ & $0.60 \pm 0.04$ & $3.4 \pm 0.5$ & 5.6 \\
$+1(5)$ & $677 \pm 53$ & $1.50 \pm 0.08$ & $2.6 \pm 0.4$ & 1.7 \\
Adult $(8)$ & $280 \pm 34$ & $0.72 \pm 0.02$ & $1.2 \pm 0.3$ & 1.7 \\
\hline
\end{tabular}


Behavior of fetal and adult cytidylyltransferase on biogel $A 1.5$

The $100000 \times g$ supernatant from -2 day fetal lung and from adult lung was fractionated with $\left(\mathrm{NH}_{4}\right)_{2} \mathrm{SO}_{4}$. The cytidylyltransferase activity was precipitated between 28 and $40 \%$ saturation. The protein in this fraction was dissolved in $50 \mathrm{mM}$ potassium phosphate $/ 0.145 \mathrm{M} \mathrm{NaCl}, \mathrm{pH} 6.0$, and chromatographed on a column of Biogel A 1.5 previously equilibrated in the same $\mathrm{NaCl}$ buffer. The major portion of the adult activity was eluted at the void volume (Fig. $4 \Lambda$ ). This activity did not require the addition of phospholipid for activity. A smaller amount of activity, which was only measurable in the presence of phospholipid, was eluted slightly ahead of the lactic dehydrogenase marker and well separated from the first peak of activity. All the fetal activity was eluted in a single peak which corresponded to the phospholipid requiring peak seen in the adult (Fig. 4B). This activity also required the addition of phospholipid for activity. Similar elution profiles were obtained with supernatant prior to $\left(\mathrm{NH}_{4}\right)_{2} \mathrm{SO}_{4}$ fractionation.

Cytidylyltransferase apparently exists in two forms, one with a high molecular weight that does not require phospholipid and one with a lower molecular weight which does require phospholipid for activity. The activity in fetal lung is predominantly the low molecular weight species. Furthermore, incubation of the fetal enzyme with lipid appears to convert the low molecular weight form to the high molecular weight form (Fig. 4C).

\section{Discussion}

Although the properties of cytidylyltransferase from liver and brain have been investigated in some detail [19-25], relatively little has been reported concerning the properties of lung cytidylyltransferase. Thom and Zachman [26] reported preliminary characterization of cytidylyltransferase from human neonatal lungs. The apparent $K_{\mathrm{m}}$ for CTP was estimated to be $2.0 \mathrm{mM}$, a value about 3-fold higher than out estimate for rat lung. The apparent $K_{\mathrm{m}}$ for phosphocholine of $0.25 \mathrm{mM}$ reported for human lung was about 4-fold lower than our apparent $K_{\mathrm{m}}$ for rat lung. The $\mathrm{pH}$ optimum for neonatal human lung is similar to our results for rat lung. However, the studies with neonatal human lung used whole tissue homogenates only, and did not investigate the subcellular localization or any possible phospholipid effects on the enzyme activity. Chida et al. [27], have investigated the activity of cytidylyltransferase in fetal and adult rat lung homogenates, but did not study in any detail the relative properties of the enzyme.

There are significant differences between the properties of cytidylyltransferase from fetal lung and from adult lung. The activity in adult lung supernatant is only minimally stimulated by the addition of phospholipid; whereas the major portion of the enzyme in fetal lung supernatant is in an inactive form, which requires phospholipid for activity. This property is similar to that for cytidylyltransferase from other tissues $[19,20,28]$. However, in marked contrast to the results reported for other tissues, lung cytidylyltransferase is stimulated rather specifically by inositol phosphoglycerides and serine phosphoglyceride, only slightly activated by lysophosphatidylcholine, and not activated at all by choline phosphoglycerides. The ability of isolated phospho- 

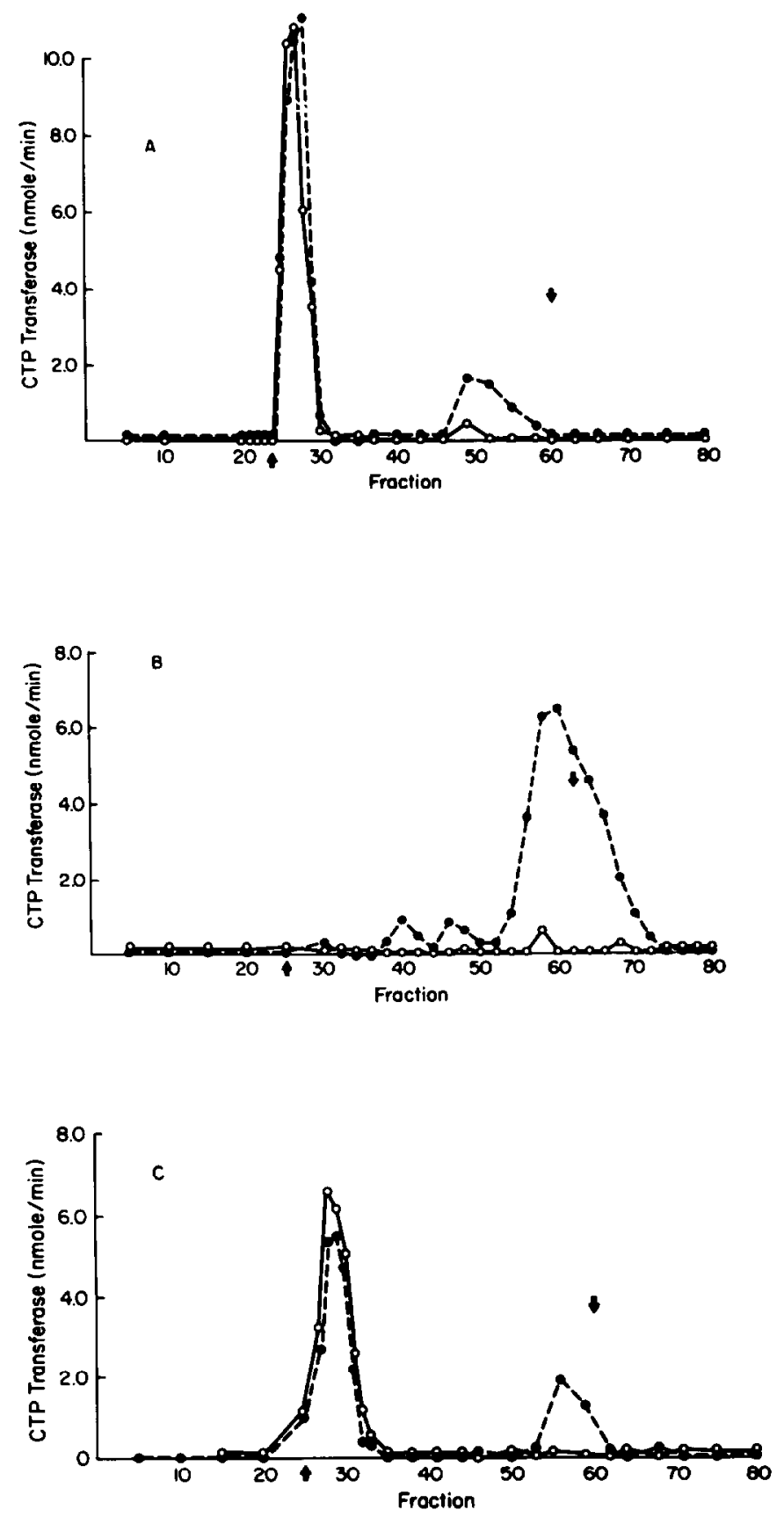

Fig. 4. Gel filtration chromatography of cytidylyltransferase. A column of Biogel A $1.5(1 \times 75 \mathrm{~cm})$ was equilibrated with $50 \mathrm{mM}$ potassium phosphate buffer (pH 6.0)/0.145 M NaCl. The ammonium sulfate fraction (28-40\% saturation) from $100000 \times g$ supernatant was dissolved in the $\mathrm{NaCl}$ buffer so that the protein concentration was $30 \mathrm{mg} / \mathrm{ml}$. A $1.0-\mathrm{ml}$ portion was applied to the column. A small amount of lactic dehydrogenase was added to the $1.0-\mathrm{ml}$ sample prior to application. Fach fraction contained $2.0 \mathrm{ml}$. $\longrightarrow$, activity without added lipid; $\longrightarrow$, activity in presence of $1.0 \mathrm{mM}$ lipid; $\uparrow$, void volume of column as measured with blue dextran; $\$$, the elution position of lactic dehydrogenase; $A$, adult; $B,-2$ day fetal; $\mathrm{C},-2$ day fetal preincubated for $10 \mathrm{~min}$ at $37^{\circ} \mathrm{C}$ with $1.0 \mathrm{mM}$ lung lipid prior to application on the column. 
lipids to activate the enzyme appears to be dependent upon the isolation procedure and presumably is a reflection of the degree of alteration of the active phospholipid. Thus, the discrepancies between our results with lung and the results for other tissue may reflect the methodology of phospholipid purification and storage as well as possibly tissue differences.

The inactive cytidylyltransferase is significantly smaller in size than the active form. This is clearly demonstrated on Biogel A 1.5 columns, particularly with fetal enzyme. The preincubations of fetal enzyme with lipid apparently activate the enzyme by forming a lipid-protein complex of high molecular weight. We do not have sufficient data at this time to determine if this phenomena involves a subunit interaction which is dependent upon the presence of phospholipid or whether it reflects a binding of phospholipid to the molecule without any protein-protein interactions.

A comparison of the developmental profile for cholinephosphate cytidylyltransferase activity with the incorporation of $\left[\mathrm{CH}_{3}-{ }^{14} \mathrm{C}\right]$ choline into choline phosphoglycerides by lung slices [5] indicates that increased enzyme activity is not solely responsible for the increased capacity of lung slices to synthesize choline phosphoglycerides. Both activities are at $20-30 \%$ of adult at -4 day through -2 day fetal lung; however, at -1 day, the incorporation of $\left[\mathrm{CH}_{3}-\right.$ ${ }^{14} \mathrm{C}$ ]choline rapidly increases to adult levels, while the activity of cholinephosphate cytidylyltransferase remains at $40 \%$ of the adult. Chida et al. [27] also reported similar comparative data which showed that the incorporation of $\left[\mathrm{CH}_{3}{ }^{-14} \mathrm{C}\right]$ choline into choline phosphoglycerides by minced lung from 1-day old rats was significantly higher than adult, whereas the activity of cholinephosphate cytidylyltransferase remained at about $50 \%$ of the adult. However, they observed a rather good correlation postnatally, since both activities reached maximal values in $5-7$ day-old animals.

The relationship between the phospholipid concentration in the supernatant and the proportion of active enzyme suggests that the controlling factor during development may be the level in the tissue of a specific species of phospholipid, presumably an inositol phosphoglyceride and/or a serine phosphoglyceride, perhaps with specific fatty acid composition. A true assessment of the in vivo significance of the activation phenomena cannot be determined until additional information is obtained. However, if the activity measured in the absence of phospholipid is a valid reflection of the in vivo state, the activation phenomena may play a significant role in the developmental control of choline phosphoglyceride synthesis in the lung.

Although Farrell [29] has proposed that the reaction catalyzed by cholinephosphotransferase (CDP-choline : 1,2-diacylglycerol cholinephosphotransferase, EC 2.7.8.2) is the rate-limiting step in the synthesis of choline phosphoglyceride by the lung, evidence from studies in other tissues indicates that the choline phosphotransferase reaction does not have the characteristics of a ratelimiting reaction. The reaction appears to be reversible and to operate at near equilibrium [9,30,31]. Radioisotope experiments by Moriya and Kanoh [32] indirectly suggest that this reaction is also reversible in vivo in the lung. Furthermore, studies on the regulation of phospholipid biosynthesis by rat hepatocytes and brain have suggested that under physiological conditions the availability of CDPcholine is rate-determining and thus, the reaction catalyzed by 
cholinephosphate cytidylyltransferase is the rate-limiting step [33-36]. Although no conclusive evidence exists for the rate-determining role of cholinephosphate cytidylyltransferase in the lung, our previous results with rat lung slices [5], in addition to the above considerations, suggests a regulatory function for this reaction.

\section{Acknowledgments}

This work was supported by the Veterans Administration and by Grant HD 02871 from the National Institute of Child Health and Human Development and by Grant GM 00187 from National Institute of Health.

\section{References}

1 Weinhold, P.A, and Villee, C.A. (1965) Biochim. Biophys, Acta 106, 540-550

2 Buckingham, S., McNary, W.F. and Sommers, S.C. (1964) Science 145, 1192-1193

3 Brown, E.S. (1965) Am. J. Physiol. 207, 402-406

4 Morgan, T.E., Finley, T.N. and Fialkow, H. (1965) Biochim. Biophys, Acta 106, 403-413

5 Weinhold, P.A. (1968) J. Lipid Res. 9, 262-266

6 Morgan, T.E. (1971) Arch. Int. Med. 127, 401-407

7 Wolfe, B.M.J., Anholdt, B., Beck, J.C. and Rubinstein, D. (1970) Can. J. Biochem. 48, 170-177

8 Spitzer, H.L., Morrison, K. and Norman, J.R. (1968) Biochim. Biophys. Acta 152, 552-558

9 Bjornstad, P. and Bremer, J. (1966) J. Lipid Res. 7, 38-46

10 Wells, M.A. and Hanahan, D.J. (1969) Methods Enzymol. 14, 178-184

11 f.nsell, G.B. and Chojnacki, T, (1969) Methods Enzymol. 14, 121-128

12 Folch, J., Lees, M. and Sloane-Stanley, G.H. (1957) J. Biol. Chem. 226, 497-509

13 Sweeley, C.C. (1969) Methods Enzymol, 14, 254-267

14 Rouser, G.. Kritcheusky, G., Gamamoto, A., Simon, G., Galli, G. and Bawmen, J. (1969) Methods Enzymol, 14, 272-317

15 Skipski, V.P. and Barclay, M. (1969) Methods Enzymol. 14.530-598

16 Lowry, P.H., Rosebrough, N.J., Farr, A.L, and Randall, R.J. (1951) J. Biol. Chem, 193, 265-275

17 Marinetti, G.V. (1967) Lipid Chromatographic Analysis, Vol. 1, p. 118, Marcel Dekker, Inc., N.Y.

18 Levey, G.S. (1971) Biochem. Biophys. Res. Commun. 43, 108-113

19 Fiscus, W.G, and Schneider, W.C. (1966) J. Biol, Chem, 241, 3324-3330

20 Chojnacki, T., Radominska-Pyrek, A. and Korzybski, T. (1967) Acta Biochim. Pol. 14, $383-388$

21 Kennedy, E.P. and Weiss, S.B. (1956) J. Biol. Chem. 222, 193-213

22 Schneider, W.C. and Behki, R.M. (1963) J. Biol, Chem. 238, 3565-3571

23 Schneidex, W.C. (1963) J. Biol. Chem. 238, 3572-3578

24 Procellati, G. (1969) Drugs Affecting Lipid Metabolism (Holmes, W.L., Carlson, L.A. and Paoletti, R., eds.), pp, 295-306, Plenum Press, New York

25 Borkenhagen, L.F. and Kennedy, E.P. (1957) J. Biol. Chem. 227, 951-961

26 Thom, M.L. and Zachman, R.D. (1975) Pediat, Res. 9, 201-205

27 Chida, N., Hirono, H., Nishimura, Y. and Arakawa, T. (1973) Tohoku J. Exp. Med. 110, $273-282$

28 Procellati, G, and Arienti, G. (1970) Brain Res, 19, 451-464

29 Farrell, P.M. (1973) Respiratory Distress Syndrome (Villee, C.A., Villee, D.B. and Zuckerman, J., eds.), pp. 311-341, Academic Press, New York

$30 \mathrm{Kanoh}, \mathrm{H}$. and Ohno, K. (1973) Biochim. Biophys, Acta 306, 203-217

31 Sundlex, R., Akesson, B. and Nilsson, A. (1974) Biochim. Biophys. Acta 337, 248-254

32 Moriya, T. and Kanoh, H. (1974) Tohoku J. Exp. Med. 112, 241-256

33 Sandler, R. and Akesson, B. (1975) J. Biol. Chem. 250,3359-3367

34 Mandel, P. and Edel-Harth, S. (1966) J. Neurochem. 13, 591-595

35 Gomez, N.U., Uomino, E.F.* Santiago, J.C. and Sellinger, U.Z. (1971) Neurobiology 1, 103-114

36 Possmayer, F. (1974) Biochem. Biophys. Res. Commun, 61, 1415-1426 